\title{
Design and the customer experience: the challenge of embodying new meaning into a new service
}

Federico Artusi ${ }^{1}$, Emilio Bellini ${ }^{1}$

${ }^{1}$ Department of Management, Economics and Industrial Engineering, Politecnico di Milano, Milano, Italy.

This is a post peer-review, pre copy-edit version of an article published in Creativity and Innovation Management. The final authentic version is available online at: https://doi.org/10.1111/caim.12364

\begin{abstract}
Innovation of Meaning is a framework that aims to innovate the "reason why" people use a product or service. However, as current research is limited to the strategic generation phase, we lack an understanding of how to embody new meaning in a new solution. This gap is critical, as development teams may pursue a reinterpretation of meaning strategy, causing the intended meaning to substantially differ from the constructed meaning. Moreover, the current dominant approaches derive from the design disciplines, which are founded on the opposite principles (outside-in vs inside-out). This study presents a new concepting method in line with the core principles of the IoM framework, testing its effectiveness through an experiment with 77 managers from 33 Italian retailers. Findings indicate that the service concept needs to be simple and focused on one specific element (moment) in the customer journey. This "Moment of Meaning" takes the role of a metaphor for the whole service, and allows a coherent but flexible operationalization of the new meaning strategy in the customer experience.
\end{abstract}

Keywords: Innovation of Meaning, Design, Customer Experience, Service Concept

(C) this manuscript version is made available under the CC-BY-NC-ND 4.0 license. https://creativecommons.org/licenses/by-nc-nd/4.0/ 


\section{INTRODUCTION}

Recent years have seen an increasing overlap of theory and practice in the innovation and new product development domain. Stimulated by the growing number of practitioner articles, researchers have been challenged to develop and describe new methodologies and frameworks that can be applied in practice. These frameworks can be divided into two main categories. The first specifically refer to designing a new solution for an identified problem, such as the Lean Startup (Ries, 2009), Design Thinking (Brown, 2008), or Agile (Knapp, Zeratsky, \& Kowitz, 2016) approaches. With different principles and processes, they aim to provide ways to design a new solution in response to a need, problem, or opportunity. Companies can select (or mix) the most appropriate approaches to develop a new solution: Design Thinking may be helpful in defining promising ideas to develop at an early stage; Lean Startup may help in rapidly generating prototypes and testing them; Agile may be needed to further cyclically refine the new product and quickly bring it to market. The second set of approaches is more strategic, related to redefining the long-term value drivers that underpin the identification of the needs, problems, and opportunities. The Blue Ocean (Kim \& Mauborgne, 2004) and Job to Be Done (Christensen, Hall, Dillon, \& Duncan, 2016) frameworks offer powerful insights for studying new forms of innovation strategies that allow assessing the existence of an uncontested market space, or deeply investigating real needs and how new products can help customers in their life experience.

A further approach, Innovation of Meaning (IoM) (Verganti, 2017), aims at studying the success of the innovation strategies at a different level. Rather than identifying new or existing problems to be solved, it entails conceptualizing new meanings that people will give to specific products and services. This is pursued with some key principles: the orientation towards critical questioning, the interpretation of socio-cultural transformation, and a pure 
inside-out approach where the new meaning derives from the internal envisioning of executives and designers (Verganti, 2009, 2017).

In dealing with the IoM process, Verganti (2009) defines two domains: the direction, which consists of the new meaning as a unifying logic that gives coherence to the actions and design efforts, and the solution, which is the set of decisions that embody the new meaning in specific functional requirements and moments of the customer experience. However, the last step of the process is still poorly described (Eling \& Herstatt, 2017), especially in the context of services (Takeyama, Tsukui, Yamaguchi, \& Matsuo, 2016). Previous studies describe the means of instantiating meaning in products by coherently shaping their language through tangible characteristics, such as form, aesthetic, or color (Norman, 2004; Dell'Era, Buganza, Fecchio, \& Verganti, 2011; Steffen, 2009), which is especially critical when dealing with services due to their intangibility (Edvardsson, Gustafsson, \& Roos, 2005) and the high importance of human factors in the delivery phase (Bettencourt \& Gwinner, 1996). As we will show in the following, this is in contrast with the IoM principles and potentially harmful in pursuing radical innovation (Candi, van den Ende, \& Gemser, 2016). Our study aims to understand how to enable switching from a meaning strategy to new service development, where the service concept has a dominant role (Lovelock, 1999). Thus, our research question is: How can the service concept be shaped to effectively embody new meaning in a new service?

The article is organized as follows: In the first section, we dig into the IoM concept to deeply explore the origins and principles within new product development studies. In the second section, we highlight and detail the design problem of switching from an innovation strategy to service design. In the third section, we propose an ad hoc concepting method to embody new meaning in a new service concept. Thereafter, we consider two hypotheses tested through an experiment. We discuss our findings in the last section. 


\section{THE INNOVATION OF MEANING FRAMEWORK}

Csikszentmihalyi and Halton (1981, p. 1) state, "Things people interact with are not only tools for survival, they embody goals, manifest and shape user's identity". Product meaning is defined as the general cultural definition of the product itself (Domzal \& Kernan, 1992). This is related to the evolution of socio-cultural paradigms, since giving meaning to an object is not only an individual action but emerges from exposing a social group to the specific object. Meaning-making is a process of making sense of what is perceived during any kind of activity. While the experience may belong to the single individual, the meaning-making process is highly influenced by society. As Kurzman (2008, p. 6) states, "Meaning-making refers to collective contest over interpretation". This implies that the individual's ability to interpret and give meaning to a tangible or intangible object is affected by interpretation classes that society provides at a specific time. Verganti and Öberg $(2013$, p. 87) call it "the existing paradigmatic interpretation" of a piece of offering. The role of the dominant culture, determining how artifacts can be interpreted, is central in the perception of meanings (Arnould \& Thompson, 2005).

The potential of design, intended as a meaning-making activity, is further recognized in innovation studies (Utterback et al., 2006; Bloch, 2011; Eisenman, 2013; Calabretta \& Kleinsmann, 2017), raising the need to leverage design to explain a new typology of radical innovation (Verganti, 2009). Verganti directly builds on the work of Krippendorff (1989) and Krippendorff and Butter (2008) advocating design as a way to give meaning to artifacts. In his book, Verganti (2009) defined what is known as the IoM paradigm, namely design as an approach to innovate the "reason why" (the meaning) people purchase a product or service. In one of his most famous examples, Verganti (2011) describes the case of Wii. In 2006, gaming was intended as a way to exit from physical reality and immerse in a deep, virtual one. Nintendo changed the meaning by providing a product whose use was meant to be 
social: gaming as a way to connect deeper with family or friends in the real world through virtual support. Changing the meaning of the console allowed exiting from an overcompetitive market and becoming the leading game console in terms of units sold. The IoM framework was then further explored in its relation to technology. The different application of technology to enable a new meaning leads to what is known as a "technology epiphany" (Verganti, 2011; Buganza, Dell'Era, Pellizzoni, Trabucchi, \& Verganti, 2015; Dell’Era, Altuna, Magistretti, \& Verganti, 2017). At the same time, other studies helped in understanding the difference between this new approach and other design school approaches, such as User-Centered Design and Participatory Design (Abras, Maloney-Krichmar, \& Preece, 2004; Schuler \& Namioka, 1993), and Open Innovation (Chesbrough, 2006). In particular, the study of Candi et al. (2016) identified user involvement as a key factor of incremental innovation success, while an inside-out approach, such as IoM, was understood as more appropriate for radical innovation. These efforts helped researchers in the conceptualization of the IoM process, synthesized in the work of Verganti (2017).

\section{(Insert Figure 1 about here)}

As Figure 1 shows, the process consists of three main steps:

- The first aims to understand the current meaning in a given category of products/services, often represented by the dominant design.

- The second involves generating a new meaning through a process of interpretation and criticism (Verganti, 2017).

- The last deals with embodying the meaning in a product or service: this phase consists in the various actions that can be taken to develop the new product/service.

In the last pages of his book, Verganti (2017) leaves this third step open to further research, since he only briefly recalls the established mechanisms of new product development, such as user need analysis, probing and beta testing, minimum viable products. 
The next section discusses the need to better understand how to face the challenge of embodying this kind of abstract vision of the interpretation of societal and technological evolution in concrete design choices for the development of a new service.

\section{CHALLENGES IN DEVELOPING THE IOM SERVICE CONCEPT}

In a comprehensive literature review on the very early phase in the new product developmen process where strategy formulation and concept development take place and decisions about specific requirements are taken, Eling and Herstatt (2017) highlight that the high potential of the IoM framework needs more insights on how to best organize and manage the Front End of Innovation (FEI) . FEI is usually described as the set of activities preceding the formal start of NPD or the first phase that formal NPD processes involve (Dewulf, 2013). FEI is defined as a critical step both in incremental and radical innovation processes (Barczak, Griffin, \& Kahn, 2009; Sakellariou, Karantinou, \& Goffin, 2017). Building on the literature, Eling \& Herstatt (2017) define the FEI process as in Figure 2.

\section{(Insert Figure 2 about here)}

This formulation of FEI can help in understanding some of the organizational challenges of vision alignment and shared interpretation that are specific to the embodiment of an IoM strategy in a new service concept. The challenge derives from the conceptual difference between "ideation", i.e., a creative outside-in formulation of new solutions for a set of problem-solving needs, and "vision", i.e., the intuitive inside-out envisioning of a new meaning for the deeper cognitive and affective engagement of users resulting from a critical interpretation (Verganti, 2017). The intrinsically vague and personal nature of meanings requires a common interpretation and visualization enacted and shared among innovation teams (Press et al., 2019). This specific nature of IoM, founded on interpreting and 
envisioning (Verganti \& Öberg, 2013), exaggerates the traditional innovation issue of aligning those involved in designing a single output (Dougherty, 1992).

The interpretive effort that IoM entails requires taking into account the vagueness and intangible nature of meanings, that are constantly subject to reinterpretation based on individual and contextual factors (Grayson \& Martinec, 2004). Their vagueness is well represented by the difference between the intended, constructed, and reconstructed meaning (Kazmierczak, 2003). The issue here is that meanings can hardly be fixed: any human activity implies the continuous interpretation of the signs that may be experienced (Deely, 1986), leading to the constant reconstruction of meanings. For this reason, the intended meaning, the meaning strategy (Battistella, Biotto, \& De Toni, 2012), and the constructed meaning, may consistently differ based on the reinterpretation of the development teams.

In design studies, the organizational task of maintaining alignment on the vision is given to metaphors (Verganti, 2009; Dell'Era et al., 2011). The metaphor, intended as a sign that represents the meaning of something else (Lakoff \& Johnson, 1980), is a powerful tool to keep people aligned over the meaning at the strategic level. This in turn increases coordination in a common effort (Okhuysen \& Bechky, 2009). Although effective on the strategic side of innovation, metaphors are too vague to guarantee alignment during development phases. In these phases, the problem is no longer sharing the same vision but sharing the same design approach in terms of how to convey the vision to customers (Dougherty, 1992). In line with Lovelock and Wirtz (2004), we argue the need for a new service concept as a metaphor for the entire service. Differently from Clark, Johnston, and Shulver (2000), we deem that the first version of the service concept should not encompass information on the value, form, function, experience, and outcome. Coherently with the IoM nature, it should be representative of the new value and how customers experience it. In the same way that a metaphor can keep teams aligned over the new meaning strategy (Jonczyk 
Sédès, 2019; Jamrozik, McQuire, Cardillo, \& Chatterjee, 2016), the service concept would be responsible for keeping individuals aligned on how to deliver it to customers (Goldstein, Johnston, Duffy, \& Rao, 2002).

The service design literature suggests the adoption of customer journeys and service blueprints to represent and build the new service (Bitner, Ostrom, \& Morgan, 2008; Patrício, Fisk, Falcão e Cunha, \& Constantine, 2011; Teixeira et al, 2017; Følstad \& Kvale, 2018). However, even the simplest one, customer journey mapping, being focused on all the backand front-end of the service, is too complex to serve as a practical representation of the new meaning. Avoiding the over-complexity of the concept is in fact necessary so as not to impede the development of an effective solution (Seidel \& O'Mahony, 2014). Thus, we propose a new method for the service concept that observes the need for simplicity and clarity in the first stages of service development. As shown in Figure 3, the new proposed method, which we call "Moment of Meaning", is intended to connect the cognitive power of metaphor as an abstract method for a common understanding of the new meaning strategy, and the descriptive power of the customer journey map as a practical tool for a detailed description of the new physical and multisensory interactions between the user and the front end of the service.

(Insert Figure 3 about here)

\section{THE MOMENT OF MEANING}

We propose an approach based on the design of a single interaction during the customer experience. This interaction, or moment in the experience, should be the practical translation of the new meaning into a part of the solution. This interaction cannot be misinterpreted by those working on the development of the service. In later stages, the service system is further detailed around this initial and clear interaction that serves as the cornerstone of the new customer experience. We call it "Moment of Meaning" (MoM from now on), functioning as 
an exemplary practical translation of the new meaning. As the reference of what the new meaning actually means, it allows avoiding misinterpretations by the development teams. In our study, MoM is an organizational tool that informs service development, and may eventually be visible to customers. An interesting contribution in this vein is that of Bolton, Gustafsson, McColl-Kennedy, Sirianni, and Tse (2014) identifying the concept of "small details", which are specific aspects of the service that cannot be aligned with the competitors' offering. The authors directly build on the definition of Gremler (2004), for whom small details have a direct and profound effect on the customer experience, which depends on specific elements rather than the sum of service interactions (Beltagui, Darler, \& Candi, 2015). In this case, small details are a way to communicate competitive advantage. Similarly, MoM is a small detail in charge of communicating both internally and externally that the meaning of a service has changed.

We argue that through the design of the single most important moment, development teams would be aligned around the core offering, ensuring the desired meaning is conveyed to customers. At the same time, as the solution is not yet at the complex system level, it can be adapted to the specific context. As the metaphor is in charge of maintaining alignment at the strategic level of innovation, the moment of meaning absolves the function at the beginning of the development phase. We frame two hypotheses to be tested through an experiment.

H1: MoM allows the more effective alignment of development teams around the new envisioned meaning.

A problem specific to the development of radically new products and services is their communicability to internal and external stakeholders, and avoiding misinterpretations (Dougherty, 1992). The ability to correctly represent the new product or service is in fact a key element of ensuring a common understanding and sharing it (Okhuysen \& Becky, 2009; 
Leonardi, 2011). As for metaphors in the strategic IoM phase (Verganti, 2009), we argue that working on a single element in the service concept allows keeping the different actors aligned on the envisioned new meaning. This is in line with Goldstein et al. (2002) for whom a key feature of the service concept is granting organizational alignment. This is especially critical in the case of radical innovation in services, where the activities are extremely uncertain and dynamic (O'Connor \& Rice, 2013), and value delivery depends on customers to front-end the employees' relationship (Vargo \& Lusch, 2008; Engen \& Magnusson, 2018). Therefore:

H2: MoM allows the higher scalability of the service concept over different services.

Scalability is a crucial concern when designing a new retail service that usually needs to be adapted to numerous and heterogeneous locations (Ailawadi \& Farris, 2017). Retail services are characterized by several constraints (square meterage, location...) that increase the difficulty of implementing the same concept in different stores. In addition, retail is a high people-intensive service, which increases the scalability issues (Berry et al., 2006). Retail services must be flexible to adapt to the single customer and enable the co-creation mechanisms (Grönroos, 2011) that occur at the individual customer level and positively influence the quality perceived (Schnurr, 2017). For this reason, given that the proposed MoM aims at freezing a single moment in service consumption, we argue that it would enable its easier replication in different locations and greater flexibility in adapting the overall service.

\section{METHODOLOGY}

We set up a laboratory experiment (Harrison, Harstad, \& Rutström, 2004; Levitt \& List, 2009) to support our conceptual reflections and test the appropriateness of MoM. We chose a laboratory setting against a field experiment to minimize the external variables and increase 
internal validity. The experiment was aimed at understanding how service development teams work and highlight the difference in outcome between teams that work with the newly proposed concepting method (MoM) compared to those working with the traditional Customer Journey (CJ). Given the need to simulate a complex process, the population was selected from among the participants of a series of workshops held by the authors with managers, technologists, and designers working in the retail business. We decided to focus on retailing for two critical reasons:

- Retail services are characterized by a high degree of human intervention in service design and delivery (Kim \& Kim, 2012), which could lead to several possibilities of mis-interpretation of the new meaning. Thus, this is a critical sector in which to test the new method and its effectiveness.

- Retailing is currently at the center of a crisis (Petro, 2019) and it has been continuously innovated in several ways, as the omni-channel paradigm is showing (Verhoef et al., 2015). Thus, people in the sector are used to think with an innovative mindset and to evaluate the appropriateness of the methods used.

In total, 81 individuals from 33 companies participated in the experiment, either managers and employees in the largest Italian retail companies, or senior consultants of technology providers to retailers. To increase the validity of results, the participants have different backgrounds in marketing, design, financial, IT, and organization. The participants were randomly divided and assigned to different groups and teams, as shown in Figure 4.

\section{(Insert Figure 4 about here)}

In the first step, participants were randomly divided into three macro-groups:

- One assigned to the use of MoM as a concepting tool

- One assigned to the use of a traditional concepting tool 
- 20 participants split among the traditional and MoM tools to provide data for the exploratory factor analysis to test the validity of constructs.

Among the first two macro-groups, participants were further divided into smaller groups each consisting of between 10-14 individuals and assigned to an academic tutor. In the last step, individuals self-organized into the final teams of 4-6 participants. At this point, instructions for the work were provided for MoM, which uses a new process, and the CJ. Important to underline is the role of the tutors who were not involved in the working phase, but served as facilitators. The two tools were named "Concepting method 1" and "Concepting method 2" so as not to introduce any bias. All the teams received the same brief related to the design of the service concept for a new retail store to embody a new meaning. To minimize variance among the groups, the new strategic meaning was previously identified and agreed in a plenary session. At the end of the team work, a paper copy of the questionnaire was circulated to all participants. Each team received an A1 template to make it easy to work and visualize their discussion, which differed for to the two macro-groups:

Customer Journey Map (non-treated group): 6 teams had the task of responding to the brief using the classic CJ approach.

Moment of Meaning (treated group): 6 teams had the same task but focusing on a single element of the service experience.

We designed a questionnaire to explore how the two methods allow maximizing alignment and scalability in service development. The questions were agreed between the two researchers: first, each proposed a set of questions, second, a discussion among the two authors and two external researchers led to the final framework. The questionnaire is presented in Table 1. The researchers agreed in equally splitting the weights into the questions defining each construct. For the final paper questionnaire, the order of the questions was randomized. 
(Insert Table 1 about here)

\section{RESULTS}

A total of 57 entries were considered valid for the experiment questionnaire, and 20 entries in the test sample. Participants in the experiment worked in a controlled environment, separated into 4 groups, and supervised by 3 researchers. We performed a confirmatory factor analysis to ensure the identified measures explain the two independent phenomena. As Table 2 shows, the two factors account for $65.19 \%$ of total explained variance.

(Insert Table 2 about here)

(Insert Table 3 about here)

The factors loadings, as shown in Table 3, allowed confirming the existence of the two clusters, referring to the two components analyzed with the questionnaire:

- “ALI": Alignment towards the concept, measured through questions Q1, Q4, Q5, Q6.

- "SCA": Scalability of the concept, measure through questions Q2 and Q3.

To assess the reliability of the clusters, Cronbach's Alpha was calculated for each of the two components, resulting in the values shown in Table 4, which are higher than 0.7, indicating the reliability is high and adequate for the analysis (Peterson, 1994).

(Insert Table 4 about here)

After testing the questionnaire, we calculated the descriptive statistics. As can be seen from the preliminary analysis (Table 5), the mean values for each response are higher in the case of MoM, which leads to an overall higher result for both the alignment and scalability variables. The standard deviation is comparable among the two groups, not showing any anomalies in the data distribution. 
(Insert Table 5 about here)

We conducted a t-test to assess the mean difference of the two groups for each question and the two constructs. The objective was to accept or reject the null hypothesis $\left(\mathrm{H}_{0}\right)$, as opposed to the alternative $\left(\mathrm{H}_{1}\right)$ :

$\mathrm{H}_{0}$ : The mean of the two groups is the same

$\mathrm{H}_{1}$ : The mean of the two groups differs

Table 6 shows that for each question, the p-value is less or equal to the desired level of significance (0.05; Rice, 1989). Given that the p-values are lower than the significance level, we can reject the null hypothesis, concluding that the mean difference for each component is significantly different. The same reasoning can be applied to the two constructs, for which the p-value is greatly below the desired significance level.

(Insert Table 6 about here)

\section{DISCUSSION AND CONCLUSIONS}

The experiment aimed at tackling two different issues that impair the IoM process. Participants worked on a simplified version of the Customer Journey Map consisting of a single, relevant interaction (moment) in the customer experience. By focusing on a single moment, we aimed to test our two hypotheses that would demonstrate the effectiveness of such practice in concepting for IoM: alignment and scalability.

Alignment over innovation has been a critical issue since the beginning of research in the innovation domain. Especially when dealing with the front-end of innovation and switching from the innovation strategy to the innovation process, communication and alignment are crucial for effective implementation (Lightfoot \& Gebauer, 2011). Our experiment shows that by focusing on a single moment of the experience, the concept for a new retail service might 
be more effective in keeping teams aligned over the new meaning. The role of the "Moment of Meaning" is the same as that of the metaphor in the strategic phase of the innovation process. Metaphor is a powerful tool in coordinating and directing team efforts (Dougherty, 1992; Casakin, 2007), and the same holds true for the representation of a single service interaction at the solution level. This appropriate representation can direct people's efforts toward the same objective (Simon, 1996), and avoid the emergence of a plurality of efforts and related issues (Seidel \& O’Mahory, 2014). In line with Kzamierczak (2003), MoM offers a shortcut to the new meaning among many different potential ones, showing people what the new meaning actually means.

Scalability might seem in contrast with the very definition of meaning as contextdependent, personal, and subject to individual interpretation (Kurzman, 2008), making it difficult to implement the same meaning in different retail services. When proposed to the public, meanings are continuously negotiated between the company and customers (Gasparin \& Green, 2018). Instead of being finalized by the company and provided to customers, meanings are created and shaped by the interactions between these two actors (Bellini, Dell'Era, Frattini, \& Verganti, 2017) In addition, while the meaning of products can be embodied in some fixed material characteristic, such as form, color, material (Holbrook \& Hirschman, 1982), services meanings are potentially subject to a number of misinterpretations. These characteristics make designing a "one size fits all" solution difficult. At the same time, the nature of meaning does not allow designing different services without boundaries, since continued reinterpretation would likely lead to transferring different meanings according to the specific service. As our experiment confirmed, this issue can be overcome by designing the service concept halfway between the normative design, typical of the customer journey or blueprinting techniques (Bitner et al., 2008), and the nonmanaged and contextual design. MoM works by defining a cornerstone, the moment that is 
most important in transferring the meaning to customers. In this way, the company can control the effective implementation of the meaning in the solution, while adapting the service system to contextual and individual factors.

The MoM method is in line with recent developments in the customer experience literature, which argues for the need to spend most of the design effort in shaping the most relevant interactions instead of the full journey (Bolton et al., 2014; Voorhees at al., 2017). MoM solves the biggest open issue in the IoM process: the lack of conceptualization for the link between the strategy and the development process (Eling \& Herstatt, 2017). This is due to the absence of an inside-out way of transitioning to implementation. Differently from current alternatives based on the opposite principle (Verganti, 2017), MoM preserves that characteristics, and delays the intervention of customers to the testing phase. By keeping the process internal, the misinterpretation and potential change of meaning envisioned is kept

under control, allowing designing a retail service that is more aligned with the meaning strategy. As a lighthouse guides sailor in infinite navigation routes, MoM guides the receiver in the field of possibilities of potential meanings (Eco, 1989).

\section{IMPLICATIONS AND FURTHER RESEARCH}

MoM directly builds on the IoM concept by expanding the process downstream. It is the first conceptualization and test of the most critical phase in the front-end of innovation, whose management is especially critical for innovation outcomes (Goldstein et al., 2002). In addition, linking the meaning strategy (Battistella et al., 2012) with the service system solution side, MoM allows further exploring the role of customers in the IoM process. As Verganti $(2009,2017)$ states, customers only listen when the solution is tested on the market, and MoM would offer guidelines on how to design the prototypes to be tested. The construct is also relevant for practitioners, providing a practical tool for concepting the new solution in the case of IoM. This innovative way of conceptualizing would allow managers to control the 
envisioned meaning from the strategy to the solution, and effectively implement it in the service system. Given the limitations of this research, which is exploratory in nature and tested in the Italian context, further research is needed to refine our knowledge. In particular, MoM should be tested in a different context, possibly encompassing all the relevant economies, and for different services, and not only in the retail domain.

Moreover, this research only takes a service delivery perspective, ignoring the benefits for customers (Goldstein et al., 2002). Future studies could be directed at understanding how customers experience a service that delivers a new meaning, and how MoM could play a role in the interaction between the company and the customer. Finally, since meanings are context-dependent and subject to individual interpretation, studying the micro-processes that allow for individual interpretations of the proposed meaning would allow companies to understand how to shape their MoM to give customers the freedom to tailor their experience while ensuring the same meaning is correctly conveyed.

\section{REFERENCES}

Abras, C., Maloney-Krichmar, D., \& Preece, J. (2004). User-centered design. Bainbridge, $W$. Encyclopedia of human-computer interaction. Thousand Oaks: Sage Publications.

Ailawadi, K. L., \& Farris, P. W. (2017). Managing multi-and omni-channel distribution: Metrics and research directions. Journal of Retailing, 93(1), 120-135.

Arnould, E. J., \& Thompson, C. J. (2005). Consumer culture theory (CCT): Twenty years of research. Journal of Consumer Research, 31(4), 868-882.

Barczak, G., Griffin, A., \& Kahn, K. B. (2009). Perspective: Trends and drivers of success in NPD practices: Results of the 2003 PDMA best practices study. Journal of Product Innovation Management, 26(1), 3-23.

Battistella, C., Biotto, G., \& De Toni, A. F. (2012). From design driven innovation to meaning strategy. Management Decision, 50(4), 718-743.

Bellini, E., Dell'Era, C., Frattini, F., \& Verganti, R. (2017). Design-driven innovation in retailing: An empirical examination of new services in car dealership. Creativity and Innovation Management, 26(1), 91-107.

Beltagui, A., Darler, W., \& Candi, M. (2015). Measuring the deliverable and impressible dimensions of service experience. Creativity and Innovation Management, 24(3), 478492. 
Berry, L. L., Bolton, R. N., Bridges, C. H., Meyer, J., Parasuraman, A., \& Seiders, K. (2010). Opportunities for innovation in the delivery of interactive retail services. Journal of Interactive Marketing, 24(2), 155-167.

Bettencourt, L. A., \& Gwinner, K. (1996). Customization of the service experience: The role of the frontline employee. International Journal of Service Industry Management, 7(2), $3-20$.

Bitner, M. J., Ostrom, A. L., \& Morgan, F. N. (2008). Service blueprinting: A practical technique for service innovation. California Management Review, 50(3), 66-94.

Bloch, P. H. (2011). Product design and marketing: Reflections after fifteen years. Journal of Product Innovation Management, 28(3), 378-380.

Bolton, R. N., Gustafsson, A., McColl-Kennedy, J., Sirianni, N.J., \& Tse, D.K. (2014). Small details that make big differences: A radical approach to consumption experience as a firm's differentiating strategy. Journal of Service Management, 25(2), 253-274.

Brown, T. (2008). Design thinking. Harvard Business Review, 86(6), 84-94.

Buganza, T., Dell'Era, C., Pellizzoni, E., Trabucchi, D., \& Verganti, R. (2015). Unveiling the potentialities provided by new technologies: A process to pursue technology epiphanies in the smartphone app industry. Creativity and Innovation Management, 24(3), 391-414.

Calabretta, G., \& Kleinsmann, M. (2017). Technology-driven evolution of design practices: Envisioning the role of design in the digital era. Journal of Marketing Management, 33(3-4), 292-304.

Candi, M., van den Ende, J., \& Gemser, G. (2016). Benefits of customer co-development of new products: The moderating effects of utilitarian and hedonic radicalness. Journal of Product Innovation Management, 33(4), 418-434.

Casakin, H. P. (2007). Factors of metaphors in design problem-solving: Implications for design creativity. International Journal of Design, 1(2), 21-33.

Chesbrough, H. (2006). Open innovation: A new paradigm for understanding industrial innovation. Open Innovation: Researching a New Paradigm, 400, 0-19.

Christensen, C. M., Hall, T., Dillon, K., \& Duncan, D. S. (2016). Know your customers' jobs to be done. Harvard Business Review, 94(9), 54-62.

Clark, G., Johnston, R., \& Shulver, M. (2000). Exploiting the service concept for service design and development. New Service Design, 71-91.

Csikszentmihalyi, M., \& Halton, E. (1981). The meaning of things: Domestic symbols and the self. Cambridge University Press.

Deely, J. (1986). A context for narrative universals, or semiology as a pars semiotica. American Journal of Semiotics, 4 (3-4): 53-68.

Dell'Era, C., Buganza, T., Fecchio, C., \& Verganti, R. (2011). Language brokering: Stimulating creativity during the concept development phase. Creativity and Innovation Management, 20(1), 36-48.

Dell'Era, C., Altuna, N., Magistretti, S., \& Verganti, R. (2017). Discovering quiescent meanings in technologies: Exploring the design management practices that support the development of technology epiphanies. Technology Analysis \& Strategic Management, 29(2), 149-166.

Dewulf, K. (2013). Sustainable product innovation: The importance of the front-end stage in the innovation process. Advances in Industrial Design Engineering, 139-166.

Domzal, T. J., \& Kernan, J. B. (1992). Reading advertising: The what and how of product meaning. Journal of Consumer Marketing, 9(3), 48-64. 
Dougherty, D. (1992). Interpretive barriers to successful product innovation in large firms. Organization Science, 3(2), 179-202.

Eco, U. (1989). The open work. Harvard University Press, Cambridge.

Edvardsson, B., Gustafsson, A., \& Roos, I. (2005). Service portraits in service research: A critical review. International Journal of Service Industry Management, 16(1), 107-121.

Eisenman, M. (2013). Understanding aesthetic innovation in the context of technological evolution. Academy of Management Review, 38(3), 332-351.

Eling, K., \& Herstatt, C. (2017). Managing the front end of innovation-Less fuzzy, yet still not fully understood. Journal of Product Innovation Management, 34(6), 864-874.

Engen, M., \& Magnusson, P. (2018). Casting for service innovation: The roles of frontline employees. Creativity and Innovation Management, 27(3), 255-269.

Følstad, A., \& Kvale, K. (2018). Customer journeys: A systematic literature review. Journal of Service Theory and Practice, 28(2), 196-227.

Gasparin, M., \& Green, W. (2018). Reconstructing meaning without redesigning products: The case of the Serie7 chair. Creativity and Innovation Management, 27(4), 401-413.

Goldstein, S. M., Johnston, R., Duffy, J., \& Rao, J. (2002). The service concept: The missing link in service design research? Journal of Operations Management, 20(2), 121-134.

Grayson, K., \& Martinec, R. (2004). Consumer perceptions of iconicity and indexicality and their influence on assessments of authentic market offerings. Journal of Consumer Research, 31(2), 296-312.

Gremler, D. D. (2004). The critical incident technique in service research. Journal of Service Research, 7(1), 65-89.

Grönroos, C. (2011). Value co-creation in service logic: A critical analysis. Marketing Theory, 11(3), 279-301.

Harrison, G. W., Harstad, R. M., \& Rutström, E. E. (2004). Experimental methods and elicitation of values. Experimental Economics, 7(2), 123-140.

Holbrook, M. B., \& Hirschman, E. C. (1982). The experiential aspects of consumption: Consumer fantasies, feelings, and fun. Journal of Consumer Research, 9(2), 132-140.

Jamrozik, A., McQuire, M., Cardillo, E. R., \& Chatterjee, A. (2016). Metaphor: Bridging embodiment to abstraction. Psychonomic Bulletin \& Review, 23(4), 1080-1089.

Jonczyk Sédès, C. (2019). Mind your metaphors: Early warning signals when rolling out strategy. Journal of Business Strategy, 40(3), 10-17.

Kazmierczak, E. T. (2003). Design as meaning making: From making things to the design of thinking. Design Issues, 19(2), 45-59.

Kim, J., \& Kim, J. (2012). Human factors in retail environments: A review. International Journal of Retail \& Distribution Management, 40(11), 818-841.

Kim, W. C., \& Mauborgne, R. (2004). Blue Ocean Strategy. Harvard Business Review, 82(10), 76-84.

Knapp, J., Zeratsky, J., \& Kowitz, B. (2016). Sprint: How to solve big problems and test new ideas in just five days. Simon and Schuster.

Krippendorff, K. (1989). On the essential contexts of artifacts or on the proposition that "design is making sense (of things)". Design Issues, 5(2), 9-39.

Krippendorff, K., \& Butter, R. (2008). Semantics: Meanings and contexts of artifacts. Product experience (pp. 353-376), Elsevier. 
Kurzman, C. (2008). Meaning-making in social movements. Anthropological Quarterly, $81(1), 5-15$.

Lakoff, G., \& Johnson, M. (1980). Conceptual metaphor in everyday language. The Journal of Philosophy, 77(8), 453-486.

Leonardi, P. M. (2011). Innovation blindness: Culture, frames, and cross-boundary problem construction in the development of new technology concepts. Organization Science, $22(2), 347-369$.

Levitt, S. D., \& List, J. A. (2009). Field experiments in economics: The past, the present, and the future. European Economic Review, 53(1), 1-18.

Lightfoot, H. W., \& Gebauer, H. (2011). Exploring the alignment between service strategy and service innovation. Journal of Service Management, 22(5), 664-683.

Lovelock, C. H. (1999). Developing marketing strategies for transnational service operations. Journal of Services Marketing, 13(4/5), 278-295.

Lovelock, C., \& Wirtz, J. (2004). Services marketing: People, technology, strategy. Journal of Services Marketing, 18(5), 413-414.

Norman, D. A. (2004). Emotional design: Why we love (or hate) everyday things. Basic Civitas Books.

O'Connor, G. C., \& Rice, M. P. (2013). A comprehensive model of uncertainty associated with radical innovation. Journal of Product Innovation Management, 30, 2-18.

Okhuysen, G. A., \& Bechky, B. A. (2009). Coordination in organizations: An integrative perspective. Academy of Management Annals, 3(1), 463-502.

Patrício, L., Fisk, R. P., Falcão e Cunha, J., \& Constantine, L. (2011). Multilevel service design: From customer value constellation to service experience blueprinting. Journal of Service Research, 14(2), 180-200.

Peterson, R. A. (1994). A meta-analysis of Cronbach's coefficient alpha. Journal of Consumer Research, 21(2), 381-391.

Petro G. (2018, January). The Bogus "Retail Apocalypse" Looks More Like a Reinassance. Forbes, 21 June. Retreived from: https://www.forbes.com/sites/gregpetro/2019/06/21/the-bogus-retail-apocalypse-looksmore-like-a-renaissance/\#49734c565ff4

Press, B. J., Verganti, R., Bellis, P., Trabucchi, D., Buganza, T., Magnanini, S., \& Zasa, F. P. (2019). Leadership and design in innovation: From process management to peopleobject interaction. Paper presented at the 26th Innovation and Product Development Management Conference, 1-31.

Rice, W. R. (1989). Analyzing tables of statistical tests. Evolution, 43(1), 223-225.

Ries, E. (2009). Minimum viable product: a guide. Startup lessons learned. Retrieved from http://www.startuplessonslearned.com/2009/08/minimum-viable-product-

guide.htmlSakellariou, E., Karantinou, K., \& Goffin, K. (2017). "Telling tales": Stories, metaphors and tacit knowledge at the fuzzy front-end of NPD. Creativity and Innovation Management, 26(4), 353-369.

Schnurr, B. (2017). How my product works and how it looks: Effects of functional and aesthetic co-creation and the role of product expertise. Creativity and Innovation Management, 26(2), 152-159.

Schuler, D., \& Namioka, A. (1993). Participatory design: Principles and practices. CRC Press. 
Seidel, V. P., \& O’Mahony, S. (2014). Managing the repertoire: Stories, metaphors, prototypes, and concept coherence in product innovation. Organization Science, 25(3), 691-712.

Simon, H. A. (1996). The sciences of the artificial. MIT press.

Steffen, D. (2009). Meaning and narration in product design. DPPI'09 Proceedings, 1-9.

Takeyama, M., Tsukui, K., Yamaguchi, H., \& Matsuo, K. (2016). Design-driven service innovation: A method to change the meaning of a service. Paper presented at the Service Design Geographies. Proceedings of the ServDes. 2016 Conference, (125) 53-64.

Tax, S. S., McCutcheon, D., \& Wilkinson, I. F. (2013). The service delivery network (SDN) a customer-centric perspective of the customer journey. Journal of Service Research, $16(4), 454-470$.

Teixeira, J., Patrício, L., Huang, K., Fisk, R. P., Nóbrega, L., \& Constantine, L. (2017). The MINDS method: Integrating management and interaction design perspectives for service design. Journal of Service Research, 20(3), 240-258.

Utterback, J., Vedin, B., Alvarez, E., Ekman, S., Sanderson, S. W., Tether, B., Verganti, R. (2006). Design-Inspired Innovation. World Scientific Books.

Vargo, S. L., \& Lusch, R. F. (2008). Service-dominant logic: Continuing the evolution. Journal of the Academy of Marketing Science, 36(1), 1-10.

Verhoef, P. C., Kannan, P. K., \& Inman, J. J. (2015). From multi-channel retailing to omnichannel retailing: Introduction to the special issue on multi-channel retailing. Journal of Retailing, 91(2), 174-181.

Verganti, R. (2009). Design driven innovation: Changing the rules of competition by radically innovating what things mean. Harvard Business Press.

Verganti, R. (2011). Radical design and technology epiphanies: A new focus for research on design management. Journal of Product Innovation Management, 28(3), 384-388.

Verganti, R. (2017). Overcrowded: Designing meaningful products in a world awash with ideas. MIT Press.

Verganti, R., \& Öberg, Å. (2013). Interpreting and envisioning-A hermeneutic framework to look at radical innovation of meanings. Industrial Marketing Management, 42(1), 8695.

Voorhees, C. M., Fombelle, P. W., Gregoire, Y., Bone, S., Gustafsson, A., Sousa, R., \& Walkowiak, T. (2017). Service encounters, experiences and the customer journey: Defining the field and a call to expand our lens. Journal of Business Research, 79, 269280 
Table 1 Experiment questionnaire: Questions and their objectives

\begin{tabular}{|l|l|l|}
\hline Code & Question & Objective \\
\hline Q1 & $\begin{array}{l}\text { The method used facilitates comprehension of the meaning for the } \\
\text { development team }\end{array}$ & Alignment \\
\hline Q2 & $\begin{array}{l}\text { The concept generated facilitates service scalability over different } \\
\text { locations and spaces }\end{array}$ & Scalability \\
\hline Q3 & $\begin{array}{l}\text { The concept generated is suitable to be implemented both in } \\
\text { flagship and small stores }\end{array}$ & Scalability \\
\hline Q4 & $\begin{array}{l}\text { The method used allows avoiding misinterpretation of the meaning } \\
\text { by front-line employees }\end{array}$ & Alignment \\
\hline Q5 & $\begin{array}{l}\text { The method used allows the vision to remain stable over the entire } \\
\text { innovation process }\end{array}$ & Alignment \\
\hline Q6 & $\begin{array}{l}\text { The method used enables the easy and non-controversial generation } \\
\text { of instructions for service employees }\end{array}$ & Alignment \\
\hline
\end{tabular}

Table 2 Principal component analysis: Total variance explained

\begin{tabular}{|c|c|c|c|}
\hline Component & Total & Variance (\%) & Cumulative variance (\%) \\
\hline $\mathbf{1}$ & $\mathbf{2 . 6 8 9}$ & $\mathbf{4 4 . 8 0 9}$ & $\mathbf{4 4 . 8 0 9}$ \\
\hline $\mathbf{2}$ & $\mathbf{1 . 2 2 3}$ & $\mathbf{2 0 . 3 8 4}$ & $\mathbf{6 5 . 1 9 4}$ \\
\hline 3 & .716 & 11.930 & 77.123 \\
\hline 4 & .550 & 9.168 & 86.291 \\
\hline 5 & .447 & 7.453 & 93.745 \\
\hline 6 & .375 & 6.255 & 100.000 \\
\hline
\end{tabular}

Table 3 Rotated components matrix

\begin{tabular}{|l|l|l|}
\hline & Component 1 & Component 2 \\
\hline Q1 & $\mathbf{0 . 6 6 1}$ & 0.302 \\
\hline Q2 & 0.196 & $\mathbf{0 . 8 7 1}$ \\
\hline Q3 & 0.093 & $\mathbf{0 . 8 7 7}$ \\
\hline Q4 & $\mathbf{0 . 7 7 3}$ & -0.036 \\
\hline Q5 & $\mathbf{0 . 7 2 8}$ & 0.217 \\
\hline Q6 & $\mathbf{0 . 7 8 6}$ & 0.123 \\
\hline
\end{tabular}

Table 4 Reliability analysis

\begin{tabular}{|l|l|}
\hline Construct & Cronbach's Alpha \\
\hline ALI & 0.743 \\
\hline SCA & 0.748 \\
\hline
\end{tabular}


Table 5 Experiment descriptive statistics

\begin{tabular}{|l|l|l|l|l|l|l|l|l|}
\hline & Q1 & Q2 & Q3 & Q4 & Q6 & Q7 & ALI & SCA \\
\hline $\begin{array}{l}\text { Customer } \\
\text { Journey (CJ) }\end{array}$ & 3.57 & 3.00 & 3.09 & 3.37 & 3.34 & 3.57 & 3.46 & 3.04 \\
\hline $\begin{array}{l}\text { Moment of } \\
\text { Meaning (MoM) }\end{array}$ & 4.07 & 3.69 & 3.55 & 3.88 & 3.81 & 4.00 & 3.94 & 3.62 \\
\hline ST DEV CJ & 0.81 & 1.16 & 1.09 & 0.94 & 0.97 & 0.92 & 0.91 & 1.13 \\
\hline ST DEV MoM & 0.68 & 1.05 & 0.94 & 0.99 & 0.94 & 0.88 & 0.87 & 0.99 \\
\hline
\end{tabular}

Table 6 T-test for mean equality, independent samples

\begin{tabular}{|l|l|l|l|l|l|}
\hline & \multicolumn{1}{|c|}{ t } & \multicolumn{1}{c|}{ gl } & \multicolumn{1}{c|}{ p-value } & \multicolumn{1}{c|}{ Difference from mean } & \multicolumn{1}{c|}{ Std error } \\
\hline Q1 & -2.942 & 75 & 0.004 & -0.5 & 0.17 \\
\hline Q2 & -2.739 & 75 & 0.008 & -0.69 & 0.252 \\
\hline Q3 & -1.99 & 75 & 0.05 & -0.462 & 0.232 \\
\hline Q4 & -2.295 & 75 & 0.025 & -0.51 & 0.222 \\
\hline Q5 & -2.136 & 75 & 0.036 & -0.467 & 0.219 \\
\hline Q6 & -2.084 & 75 & 0.041 & -0.429 & 0.206 \\
\hline ALI & -3.179 & 75 & .002 & -.476 & .1498 \\
\hline SCA & -2.682 & 75 & .009 & -.576 & .2148 \\
\hline
\end{tabular}




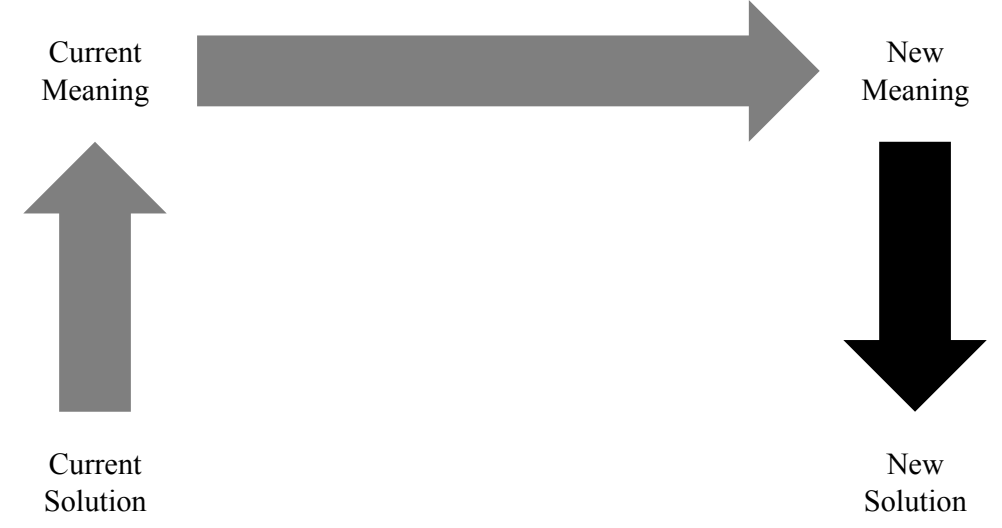

Figure 1 The Innovation of Meaning process (adapted from Verganti, 2017) 


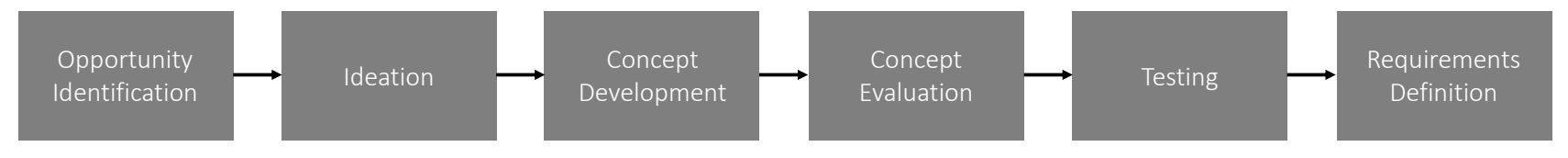

Figure 2 The Front-End of the Innovation Process (Adapted from Eling \& Herstatt, 2017) 

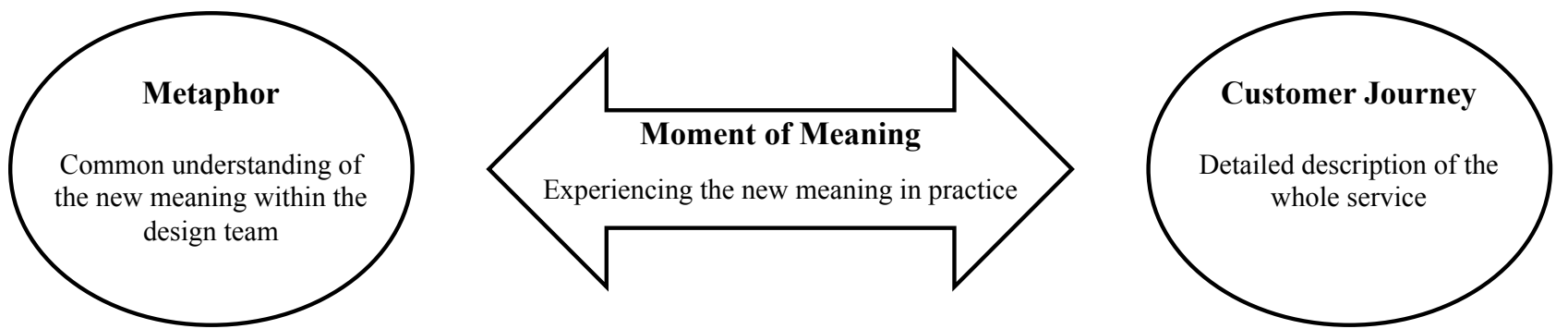

Figure 3 Moment of Meaning as a synthesis between an abstract representation of meaning and a practical description of the service 


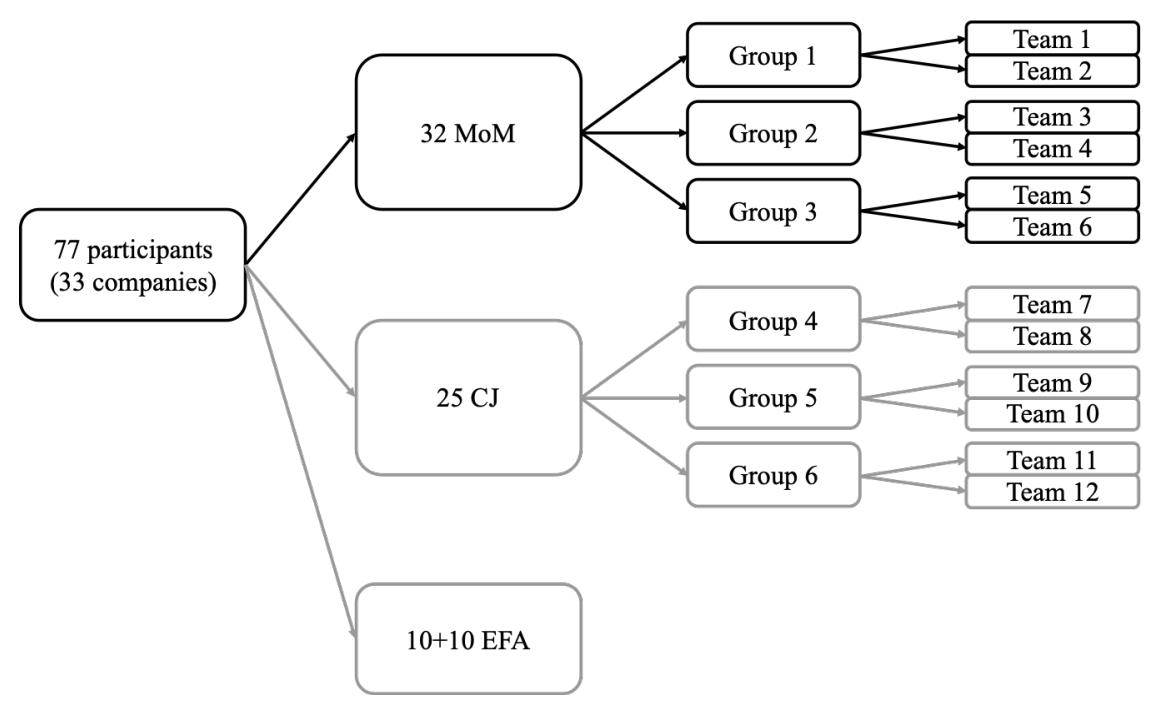

Figure 4 Group division for the laboratory experiment 